\title{
RAPID MOBILE APPLICATION DEVELOPMENT ON A PEDAGOGICAL SHOESTRING
}

\author{
Matthew A. North, Washington \& Jefferson College, mnorth@washjeff.edu
}

\begin{abstract}
University professors in computer science, information systems and technology and related disciplines face the somewhat unique and often daunting task of remaining current in a field that evolves rapidly and often dramatically over short periods of time. Within this dynamic environment, faculty typically face very real limits in terms of budget, time and resources. This paper offers a description and evaluation of an experiment in introducing mobile application development instruction within these very constraints. The paper addresses resource needs and solutions, selection and configuration of a development framework, and deployment. The paper also discusses a way in which these exercises were embedded into an existing course in Dynamic Web Development, without creating curricular or workload issues. Finally, the paper discusses some limitations associated with this approach to integrating mobile application development into an existing computing curriculum.
\end{abstract}

Keywords: Mobile Applications, Rapid Application Development, Information Systems pedagogy.

\section{INTRODUCTION}

In the past five years, the growth of mobile application development has followed a Moore's Law trajectory [16], and this industry segment shows no signs of slowing down [1]. If teaching in a discipline with such a rapid cyclical and evolutionary cycle were not challenging enough, professors in computing disciplines now face the task of developing and integrating mobile development instruction into their curricula. Students are certainly seeking these technological skills, and the industries fueling mobile innovation are looking for graduates prepared to contribute [15]. With papers to grade, committee meetings to attend, assignments and tests to write, and myriad other activities, professors face an uphill climb if they are to include mobile application development in their offerings. But we cannot simply ignore the march of technological change; computing education is already often criticized for failing to keep pace with developments in the field [4]. The purpose of this paper is to document, share, and discuss an effort to address the need for including mobile application development in an educational program within the parameters and limitations common to higher education.

\section{Challenges and Opportunities}

When asked about the most prevalent challenges faced by professors, among the most common are budget limitations. With the desire to teach mobile application development, can the department budget afford the purchase of even a few small handheld devices, let alone a full cart of iPads? If some devices are purchased, who will maintain them and how? Teaching mobile application development may seem like the right thing to do, but introducing a new topic into the computing curriculum requires far more than selecting a textbook and developing lesson plans.

Beyond finances however, there are other challenges. Teaching something new means learning something new, and that takes both time and expertise. Whether a faculty member engages in self-teaching or attends a short seminar or workshop, time will be required to learn. Once material is learned, is there time within the professor's teaching load to offer additional courses or content? If not, can older content be replaced with newer content, benefitting the student and the freshness of the educational program without creating additional work?

For this exercise, and summarized in this paper, we have found some answers to these questions and raised others along the way. The teaching of mobile application development represents an opportunity in the face of the aforementioned challenges; an opportunity to innovate, an opportunity to meet a market demand, and an opportunity 


\section{Issues in Information Systems}

Volume 13, Issue 2, pp. 248-252, 2012

for professional development. These outcomes can be realized without creating and adding new courses to the curriculum, although depending on circumstances, that route could be an option.

\section{LITERATURE}

Although the history of mobile application development, its age and timeline, could be debated ad nauseum, it is safe to suggest that the current conception of "apps" started within the past six or seven years [2,20]. The advent of the iPhone in January of 2007 can largely be credited with the mobile application revolution we have experienced in the past half-decade [10]. The rush to compete by a variety of primarily Android-based devices from essentially every major electronics maker further fueled the app explosion $[2,10]$. The complement of the iPad (and a few ensuing competitors) beginning in 2010 threw additional tinder onto the mobile fire. Indeed, perhaps writing about adding a mobile application development component to a curriculum at this date is like arriving late to the ball [17]. And yet much literature is only now coming out about the phenomenal growth of this field [12]. We now know that mobile device use, both smartphones and large- and small-form factor tablets, is not a passing fad-it has enjoyed widespread and permanent adoption worldwide $[6,7,11]$. The time is ripe for inclusion of the topic in technology oriented courses. But what is the best way to approach the integration of the topic?

Given the short life-span of most mobile application versions and the correspondent need for apps to evolve quickly, a flexible platform is needed [5]. Further, the relative impatience of most mobile app consumers demands a rapid development model coupled with easy deployment $[3,18]$. Additionally, app development must be done in a way that meets a legitimate need (in order to improve chances for adoption) [3], and can be realistically accomplished within the developer's constraints [8].

From a pedagogical standpoint, real-life adoption often takes a back seat to accomplishing learning objectives and developing skills and aptitudes in students. This is generally appropriate, as classroom projects and exercises are not always intended or designed to be commercially viable, so long as they teach students problem-solving and technical skills. There may be however opportunities for both-classroom projects which teach skills while making real products, and mobile apps make a fine laboratory for experimentation in this regard [14]. Even within the educational institution itself there may exist a real-world need for a mobile application that can be developed in the classroom [19]. With mobile device adoption at an all-time high [12], a proliferation of online resources to learn and adapt development for the mobile interface [13], supporting technologies becoming faster, more accessible and easier to use [9], and increasing demand for skilled workers in the marketplace [15], the time is right to introduce mobile development into the computing curriculum.

\section{TEACHING DESIGN AND METHODOLOGY}

The initial approach to teaching mobile application development began with a reality check. We quickly came to the realization that we likely did not have room in the curriculum to add an entirely new course. There was a significant question as to whether or not there would be room in the schedule to teach a new course with any degree of regularity. The process of proposing and gaining approval for a new catalog course that we might not be able to offer reliably added to our belief that an entire course was not the right approach for our situation. Thus, we determined that adding mobile development instruction to an existing course would be more achievable and likely, wiser.

Within our curriculum, we then evaluated a number of courses within which mobile application development could take place. A number of logical candidates were quickly identified, including the Introduction to Programming course, the Web Design and Development Course, and the Dynamic Web Development course, among others. In evaluating the projects, learning objectives and goals of each course, it became apparent that the Dynamic Web Development course was an excellent option for the introduction of mobile application content. The prerequisistes for this course were already structured in such a way as to ensure that students would have a background in programming languages, databases, and user-centered design. The barrier of entry to creating mobile applications 


\section{Issues in Information Systems}

Volume 13, Issue 2, pp. 248-252, 2012

would be much lower with students who already had a background in syntax, conditional logic, loops, arrays, and essential design concepts.

Next, the question of implementation needed to be addressed. The Dynamic Web Development course was already divided into three major student projects. It was determined that the third project could easily be re-created as a mobile application. The major course objectives for this project easily fit within the framework of a mobile application. These course objectives were first, to apply software development lifecycle methodologies to create a functional application; and second, develop an application which employs both client- and server-side functions for data exchange and delivery of dynamic content. Because the course already employed and supported HTML 5, PHP 5, CSS3, SQLLite and MySQL, mobile application development was made possible without the need for investment in additional software or hardware resources, and without the need to teach new or different languages, platforms or tools. The teaching of AJAX scripts and functions was added to the course in order to enhance the functionality and usability of students' mobile applications, however this was a minor addition which had only a slight impact on course preparation or workload.

Assessment of student learning was the final piece necessary to integrate mobile application development into the course. Figure 1 depicts the deliverables students were required to create to enable evaluation of their learning.

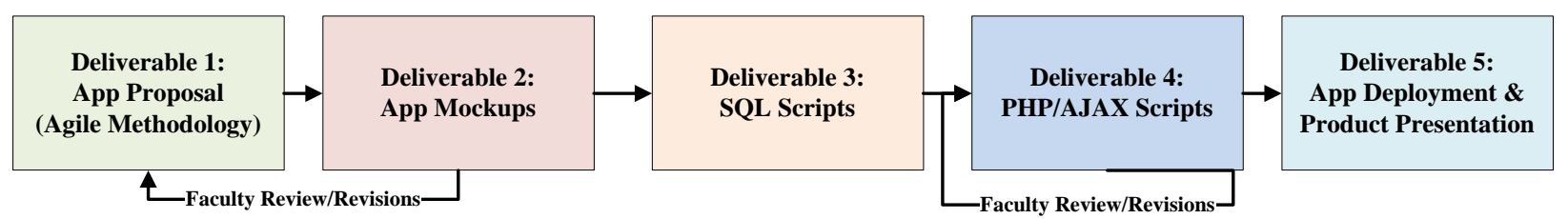

Figure 1. Mobile Application Deliverable Process

One deliverable was due each week during the five week period of the class that covered mobile applications. Because the semester was fifteen weeks in length, and the mobile application project comprised one-third of the course, five one-week deliverables were ideal for this project. The mobile application project was the last of the three in the course, so by the time students began developing their mobile applications, they had already worked extensively with HTML, PHP and the other aforementioned technologies on browser-based applications. This helped ease the barrier of entry when developing for mobile devices. Each of the deliverables were graded, however, after deliverables two and four, students whose project did not meet specified criteria were required to return and submit revisions as dictated by the instructor. Students then installed their apps on a mobile device and gave a presentation guided by a rubric used for evaluating their mobile application project.

\section{RESULTS}

The integration of mobile application development into the Dynamic Web Development class occurred for the first time during the Spring semester of 2012 (February - May). As discussed, it was positioned as the third of three projects in the class. This ended up being a wise course of action. Having the experience of developing web applications in HTML and PHP in a web browser format helped students achieve a comfort level with the development tools early on in the semester, so that the move to designing for a smaller screen and different user interface was not complicated by having to learn new programming languages or development environments. Some students did struggle in the development of Cascading Styles Sheets for smaller screens. This was not as much an issue with coding as it was a conceptual design problem for some students. By the final third of the semester, students were comfortable creating style classes and even dynamic behaviors in CSS, but some struggled to understand that their mobile applications would be more user-friendly and functional if they were not designed as tiny web pages. The penchant for designing mobile applications as small web pages appeared to occur because the students had been conditioned for the first two-thirds of the semester to think about design for a computer screen. 


\section{Issues in Information Systems}

Volume 13, Issue 2, pp. 248-252, 2012

The fact that they were using the exact same languages and technologies to develop apps that they had used for web sites caused some students to struggle with changing their design approach. This represents an opportunity for further inquiry.

For the first deliverable, students were able to propose mobile applications that were both feasible within their skill set and useful on mobile devices. In the 16-seat classroom where this pedagogical experiment took place, all students successfully proposed an acceptable mobile application. This set the stage for the second deliverable, which was for each student to mock up, using HTML and CSS, the screens for their mobile applications. The review-and-revise approach to this deliverable proved to be vital at this step in the process. It was at this point that students' difficulty in transitioning from Web browser to mobile screen became quickly apparent. By having already set an expectation with the students that they might have to revise their designs, there was little resistance when the instructor asked the students to reconsider design choices and resubmit their mockups. Having a review early on in the process helped to ensure that students did not go too far down a problematic path where students likely would have realized that their applications could not be completed or that they had major design problems.

Once a student received approval of their mockups, they were able to proceed to development of the SQL scripts necessary to handle data on the back end of their applications. Students in the class had taken an introductory database course as a prerequisite, so working with SQL was relatively elementary. A few needed a quick refresher on DDL or DML syntax, but other than that, no problems were observed at this stage of the development process.

Step four was likewise fairly straightforward for the students. Students had already developed reasonable proficiency with PHP during their first two Web browser-based projects. Adjusting to using PHP for mobile applications came fairly naturally for the students. In order to make their apps more user-friendly, several students opted to include some dynamic behaviors through jQuery Mobile. This proved to be more challenging, but was not required as part of the project. It was nice to see students going above and beyond the minimum required for their projects, though only a few of the most advanced students included these types of dynamic behaviors.

By the time students were finishing up their PHP scripts, they had been working on their mobile application projects for about one month. All but three students had functional applications by this point. The final week's deliverable was to finish, deploy and present their mobile applications. The department had accumulated a small number of different mobile devices running both Android and Apple iOS. In addition, every student but one in the class had a smartphone. Among the number of mobile application generators available today, one in particular emerged as an easy and simple tool for testing and deploying HTML and PHP-based mobile apps. AppsGeyser (www.appsgeyser.com) provides a simple method for both generating .apk packages and installing apps via a QR Code scan. Figure 2 shows the QR Code for a demo mobile app:

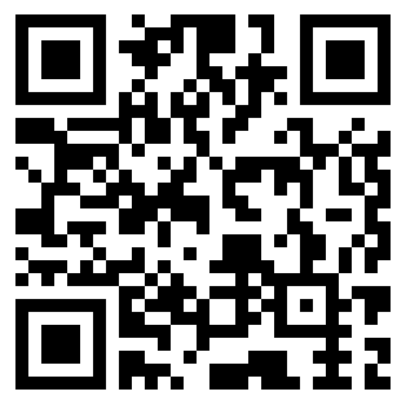

Figure 2. AppsGeyser QRCode for an in-class demo app deployment.

\section{CONCLUSIONS}

With some additional help for the small handful of students who struggled to get their apps up and running, by presentation day at the end of the final five weeks of the semester, all students had a deployable and presentable 


\section{Issues in Information Systems}

Volume 13, Issue 2, pp. 248-252, 2012

mobile application. Grades for these projects were on par with scores received by students who had taken the course in previous semesters with three browser-based projects. It should be acknowledged that the AppsGeyser approach did not give students the opportunity to compile their own .apk packages, nor did it employ a full end-to-end app development that students might get in a full mobile applications course. It did however allow every student in the class to deliver a functional mobile application within the constraints previously discussed in this paper. Every student in the class successfully built, tested and deployed a mobile application without creating a new course, without generating a substantive amount of work for the instructor, and without causing students to have to learn new technologies or languages from scratch. We are encouraged by the success of this initial attempt to integrate mobile application development into our curriculum, and look forward to improving upon our initial success.

\section{REFERENCES}

1. Ahmed, K. \& Schuegraf, K. (2011). Transistor Wars. IEEE Spectrum, 48(11), 50-66.

2. Anthes, G. (2011). Invasion of the Mobile Apps. Communications of the ACM, 54(9), 16-18.

3. Boardman, B. (2012). No App for That? Write one! Industrial Engineer, 44(3), 44-48.

4. Cohen, J. (2005). Updating Computer Science Education. Communications of the ACM, 48(6), 29-31.

5. Charland, Andre; Leroux, Brian.(2011). Mobile Application Development: Web vs. Native. Communications of the ACM, 54(5), 49-53.

6. Chiem, R., Arriola, J., Browers, D., Gross, J., Limman, E., Nguyen, P. V., Sembodo, D., Young S. \& Seal, K. C. (2010). The Critical SSuccess Factors for Marketing with Downloadable Applications: Lessons learned from selected European Countries. International Journal of Mobile Marketing, 5(2), 43-56.

7. Erman, B., Inan, A., Nagarajan, R. \& Uzunalioglu, H. (2011). Mobile Applications Discovery: A subscribercentric approach. Bell Labs Technical Journal, 15(4), 135-148.

8. Feijoo, C., Gómez-Barroso, J. L., Aguado, J. M., Ramos, S. (2012). Mobile Gaming: Industry challenges and policy Implications. Telecommunications Policy, 36(3), 212-221.

9. Garber, L. (2012). Wi-Fi Races into a Faster Future. Computer, 45(3), 13-16.

10. Greengard, S. (2010). Pew Report on Mobile Apps. Communications of the ACM, 53(11), 17-17.

11. Han, Y., Choi, Y. \& Hong, J. (2012). Experience on the Development of a ComSoc Application for Smart Phones. IEEE Communications Magazine, 50(4), 106-112.

12. Ickin, S., Wac, K., Fiedler, M., Janowski, L., Hong, J. H. \& Dey, A. (2012). Factors Influencing Quality of Experience of Commonly Used Mobile Applications. IEEE Communications Magazine, 50(4), 48-56.

13. Liu, C. L., Hsaio, W. H., Lee, C. H., Lu, G. C. \& Jou, E. (2012). Movie Rating and Review Summarization in Mobile Environment. IEEE Transactions on Systems, Man \& Cybernetics: Part C - Applications \& Reviews, 42(3), 397-407.

14. Melnik, T. (2012). Need an App? Crowdsource! Journal of Health Care Compliance, 14(1), 53-56.

15. Patel, P. (2011). Where the Jobs Are: Software Engineering Careers. IEEE Spectrum, 48(9), 28.

16. Stewart, W. (2007). The Power to Set You Free. Science, 317(5834), 55-56.

17. Taylor, D. G., Voelker, T. A. \& Pentina, I. Mobile Application Adoption by Young Adults: A Social Network Perspective. (2011). International Journal of Mobile Marketing, 6(2), 60-70.

18. Tsai, H. \& Sung, K. (2012). Mobile Applications and Museum Visitation. Computer, 45(4), 95-98.

19. Welsh, K. \& France, D. (2012). Smartphones and Fieldwork. Geography, 97(1), 47-51.

20. Zuk, R. (2012). Appalanche! Mobile Apps Proliferate as Communications Medium. Public Relations Tactics, $19(1), 7$. 